\title{
СОЦИАЛЬНО-ПСИХОЛОГИЧЕСКИЙ АСПЕКТ УПРАВЛЕНЧЕСКОЙ КОМПЕТЕНТНОСТИ РУКОВОДИТЕЛЯ
}

\section{IMPROVING THE MANAGEMENT \\ SYSTEM OF PROFESSIONAL TRAINING, ADVANCED TRAINING AND RETRAINING \\ OF SENIOR PERSONNEL OF THE MINISTRY \\ OF EMERGENCY SITUATIONS OF RUSSIA \\ O. Orlova}

Summary: The analysis of socio-psychological aspects of managerial competence of the head is carried out. The relations of the information and analytical abilities of the head and the amount of information received in the course of his professional activity are presented. The choice of the optimal leadership style is determined by the nature of the task facing the team. It is proposed to take into account the regularity of the system in relation to which management is implemented. The information and analytical abilities of the manager in relation to the initial level are considered, including the constant processes of changes and additions in terms of the volume of incoming information make it possible to assess the abilities of the manager. The complex of organizational processes as a whole is considered, the implementation of which is proposed through orientation to all groups of factors relevant to the appropriate level of competence of the head, that is, we can talk about a broad orientation of the goals of the head.

Keywords: socio-psychological competence, authoritarian leadership style, collegial style, minimization of impact in management, social and socio-psychological consequences of decisions made, classification of management styles, excessive dogmatism, inflexibility of thinking.

\author{
Орлова Ольга Николаевна \\ К.n.н., дочент, Академия государственной \\ противопожарной службы МЧС России \\ olga_on.omsk@mail.ru
}

Аннотация: Проведен анализ социально-психологических аспектов управленческой компетентности руководителя. Представлены связи информационно-аналитических способностей руководителя и объема информации по поступающей в процессе его профессиональной деятельности. Выбор оптимального стиля руководства определяется характером задачи, стоящей перед коллективом. Предлагается учет закономерности системы, в отношении которой реализуется управление. Рассмотрены информационно-аналитические способности руководителя по отношению к исходному уровню, в том числе постоянные процессы изменения и дополнения по объему поступающей информации позволяют оценить способности руководителя. Рассматривается комплекс организационных процессов в целом, внедрение которого предлагается через ориентацию на все группы факторов, актуальных для соответствующего уровня компетенции руководителя, то есть можно говорить о широкой ориентации целей руководителя.

Ключевые слова: социально-психологическая компетентность, авторитарный стиль руководства, коллегиальный стиль, минимизация воздействия в управлении, социальные и социально-психологические последствия принимаемых решений, классификация стилей управленческой деятельности, излишний догматизм, негибкость мышления.

\section{Введение}

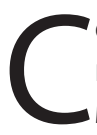

оциально-психологическая компетентность руководителя предусматривает адекватность в сфере межличностного восприятия и взаимодействия, умение предупреждать конфликтные ситуации в коллективе, гибкость стиля руководства, а также коммуникативную компетентность - способность устанавливать и поддерживать необходимые контакты с другими людьми.

Таким образом, в состав социально-психологической компетентности включается совокупность знаний и умений, обеспечивающих эффективное протекание процесса межличностного взаимодействия.

Социально-психологическая компетентность есть необходимое условие оптимальной управленческой деятельности руководителя. Именно она в значительной степени обеспечивает его лидерский статус в коллекти- ве. Руководитель - это и статус, и роль, вбирающие его характеристики и как специалиста, и как личности, в итоге - это социально-психологическая позиция. Ключевой особенностью управления в этих условиях выступает, прежде всего, умение реализовывать функцию согласованности в деятельности персонала.

Сущность социально-психологической компетентности определяется мерой связи объективных задач управленческой деятельности руководителя и субъективных возможностей его личности.

Социально-психологическая компетентность руководителя является характеристикой, концентрирующей его профессионально важные качества, и одновременно она представляет собой и состояние личности, включающее вектор ее направленности, степень ее гуманитарной подготовленности, уровень профессиональных умений (информационно-аналитических, гностических, 
проектировочных, конструктивных, организаторских, коммуникативных), базирующихся на соответствующих знаниях, навыках, способностях, которую можно отобразить в виде соотношения исходного уровня к имеющемуся объему информации в управленческом (производственном) процессе (рисунок 1).

\section{Материалы и методы}

В итоге социально-психологическая компетентность находит выражение в профессиональной готовности руководителя осознанно, своевременно и творчески решать многообразные управленческие задачи, вытекающие из динамичных условий реальной ситуации. Это личностное образование существует в общем виде как единство мотивационно-ценностного, эмоциональноволевого и содержательно-операционального компонентов и представляет собой характеристику профессионального развития личности и ее деятельности.

Основной характеристикой социально-психологической компетентности руководителя является стиль руководства.

Тот или иной стиль руководства выбирается не только потому, что он успешнее, но и потому, что позволяет в максимально возможной степени достигать актуальные в рамках реализуемой деятельности цели, соответствующие более значимой для личности системе мотивационных отношений. Соответственно, стиль руководства тесно сопряжен с характеристиками организации как системы, и с ее структурой, в которой можно выделить институциональные (формальные и технологические), внеформальные (система ролей в профессиональной группе) и неформальные (принадлежность к различного рода группировкам) подсистемы.

\section{ヘитературный обзор}

Классификация стилей управленческой деятельности, предложенная Р. Блейком и Д. Моутоном [1;2], выделяет два типа направленности профессионала-руководителя. Они названы: "заинтересованность в людях» и "заинтересованность в выполнении задачи».

На основании указанных переменных ими выделяются следующие стили управленческой деятельности:

1. Стиль, максимально ориентированный на задачу и минимально на людей. Руководитель, реализующий этот стиль, рассматривает людей как инструменты производства. Стремясь к наилучшему выполнению задачи, он мало интересуется мыслями и чувствами подчиненных. Этот стиль воплощает преимущественную субъективную значимость всего, что соответствует институциональной подсистеме организации, то есть, средствам достиже- ния цели.

2. Стиль, максимально ориентированный на людей и минимально на задачу, что сводит к минимуму проявление власти. Этот стиль в значительной степени свидетельствует о субъективной значимости неформальной подсистемы организации. Именно в рамках этой подсистемы удовлетворяются статусные потребности специалиста. Используемые при этом средства также соответствуют неформальной подсистеме отношений.

3. Стиль с минимальной ориентацией как на людей, так и на задачу. Руководитель, реализующий этот стиль, делает минимально возможное для сохранения статуса в формальной подструктуре, но так, чтобы не выступить нарушителем спокойствия в отношении других членов коллектива. Статус в формальной организации в данном случае выступает как средство для достижения целей, не отражающих цели организации. Достижение цели организации не актуально для личности даже в инструментальном контексте. При этой ориентации очень часто актуальной оказывается вне формальная система отношений, но она используется как средство достижения опять же сугубо индивидуальных целей, а именно, для сохранения статуса в формальной организации. Иначе говоря, формируется требуемое для сохранения статуса отношение «верхов» средствами вне формальной подсистемы.

4. Стиль, отражающий среднюю степень заинтересованности в людях и в задаче. Деятельность направлена на нахождение компромиссных подходов. Такой руководитель ориентирован на коллегиальное принятие решений, имея критерием выбора альтернатив мнение большинства. Подобный стиль свидетельствует о приблизительно равной ориентации на цели институциональной и неформальной подсистем, при приоритетности средств неформальной подсистемы.

5. Стиль, характеризующийся максимальной заинтересованностью в людях при максимальной направленности на задачу, что соответствует приоритетности институциональной подсистемы при равной ориентации на средства как формальной, так и неформальной организации.

Кроме того, выделяются еще два стиля: оппортунизм, характеризующийся изменчивой комбинацией стилей, ориентированных на удовлетворение сугубо эгоцентрических потребностей (цели институциональной и неформальной подсистем приобретают инструментальный характер, а спектр средств не исчерпывается теми, которые соответствуют вне формальной подсистеме), и патернализм, где ведущими оказываются мотивы поддержания и приобретения высокого статуса в неформальной и вне формальной подсистемах. Для достиже- 
ния этих целей используются средства всех подсистем, в том числе и властные полномочия.

Несколько иная модель, увязывающая мотивацию работников, их удовлетворенность и эффективность деятельности со стилем руководства, создана Т. Митчелом и Р. Хаусом (табл. 1).

Таблица 1

Отношение к человеку и стиль руководства

\section{ПРЕДСТАВЛЕНИЯ О ЧЕЛОВЕКЕ}

Модель X: по своей природе человек не склонен к труду. Предоставленный самому себе, он старается не работать или работать как можно меньше. Это означает, в0-первых, что он избегает ответственности, не стремится сделать коллективные интересы собственной целью и, в0-вторых, что труд для человека является лишь неприятной обязанностью. Его отношение к труду, таким образом, может быть только пассивным.
Модель У. По своей природе человек склонен к труду. Он не избегает ответственности, ориентирован на общественную полезность труда, находит в труде удовлетворение, вырабатывает у себя активное отношение к труду.

\section{СТРАТЕГИЯ РУКОВОДСТВА}

Мотивация. В этом случае эффективна лишь внешняя мотивация, положительная или отрицательная. Практика руководства.Пассивное отношение к труду требует авторитарного стиля руководства. В условиях, когда люди делают лишь то, что им поручают, одному руководителю приходится принимать решения, организовывать и планировать работу, распределять задачи, указывая каждому четко обозначенный вид работы. Контроль. Руководитель осуществляет постоянный и скрупулезный контроль за выполнением работы. В противном случае люди отлынивают от работы.

Мотивация. Действие внутренней мотивации достаточно эффективно. Заработок воспринимается больше как компенсация, нежели как средство стимулирования труда.

Практика руководства. Коллективный, демократический стиль руководства, ориентированный на участие членов коллектива. Руководитель своим поведением должен стимулировать такое участие.

Контроль. Решающую роль играет самоконтроль, дополняемый временами контролем со стороны руководителя и коллектива.
В соответствии с этой концепцией можно влиять на подчиненных, увеличивая для них значимость поставленных целей, либо минимизирую усилия по их достижению. На основании этих посылок выделены четыре стиля: инструментальный, стиль поддержки, стиль, поощряющий участие подчиненных в принятии решений и стиль, ориентированный на достижение.

Стиль руководства каждого начальника складывается под влиянием его профессиональной принадлеж- ности и компетентности, темперамента, особенностей характера, коммуникативной компетентности, уровня развития коллектива, сложившихся традиций и ведомственных норм. Лица с завышенной самооценкой, с недостаточной внутренней культурой, самолюбивые, неуравновешенные и агрессивные часто склонны к авторитарному стилю руководства. К нему же располагают излишний догматизм и негибкость мышления.

К демократическому стилю склонны лица с такими позитивными чертами, как объективность в оценке своих возможностей, уравновешенность, подвижность и гибкость ума, доброжелательность и чуткость к людям. Последствия авторитарного и демократического стиля руководства приводятся в табл. 2.

Таблица 2

Последствия демократического и авторитарного стиля руководства

\begin{tabular}{|c|c|c|}
\hline Показатели & $\begin{array}{l}\text { Последствия демо- } \\
\text { кратического стиля }\end{array}$ & $\begin{array}{c}\text { Последствия автори- } \\
\text { тарного }\end{array}$ \\
\hline Производительность & $\begin{array}{l}\text { относительно } \\
\text { высокая и стабильная }\end{array}$ & $\begin{array}{l}\text { колеблется между } \\
\text { высоким и низким } \\
\text { уровнем }\end{array}$ \\
\hline Прогулы & редкие & частые \\
\hline Текучесть & низкая & высокая \\
\hline $\begin{array}{l}\text { Сплоченность } \\
\text { коллектива }\end{array}$ & высокая & относительно низкая \\
\hline $\begin{array}{l}\text { Напряженность во } \\
\text { взаимоотношениях }\end{array}$ & незначительная & значительная \\
\hline Отношение к труду & $\begin{array}{l}\text { активное, } \\
\text { инициативное }\end{array}$ & $\begin{array}{l}\text { пассивное, } \\
\text { незаинтересованное }\end{array}$ \\
\hline $\begin{array}{l}\text { Ответственность } \\
\text { в труде }\end{array}$ & высокая & низкая \\
\hline Мотивация труда & $\begin{array}{l}\text { преимущественно } \\
\text { внутренние мотивы }\end{array}$ & $\begin{array}{l}\text { преимущественно } \\
\text { внешние мотивы }\end{array}$ \\
\hline $\begin{array}{l}\text { Удовлетворенность } \\
\text { трудом }\end{array}$ & высокая & низкая \\
\hline Интеграция труда & сплоченность & $\begin{array}{l}\text { разобщенность, от- } \\
\text { чуждение }\end{array}$ \\
\hline Труд как таковой & $\begin{array}{l}\text { более разнообразный, } \\
\text { сочетание исполни- } \\
\text { тельской работы с } \\
\text { участием в руковод- } \\
\text { стве }\end{array}$ & $\begin{array}{l}\text { упрощенный, высокая } \\
\text { степень разделения } \\
\text { труда, только исполни- } \\
\text { тельская работа }\end{array}$ \\
\hline $\begin{array}{l}\text { Профессиональная } \\
\text { подготовка }\end{array}$ & $\begin{array}{l}\text { стимулируется про- } \\
\text { фессиональный рост }\end{array}$ & $\begin{array}{l}\text { с определенного } \\
\text { момента професси- } \\
\text { ональный рост не } \\
\text { стимулируется }\end{array}$ \\
\hline
\end{tabular}

Сознательно выбирая тактику и стратегию управления коллективом, руководитель должен соблюдать следующие каноны оптимального руководства: 
- относиться к подчиненным корректно и внимательно, т.к. человеку свойственно тяжело переносить равнодушие, а тем более отрицательное к себе отношение руководителя;

- проявлять постоянный интерес к здоровью, настроению, интересам подчиненных;

- поручать, по возможности, сотруднику ту работу, к которой он имеет склонность;

- обязательно поощрять хорошую работу (материально и морально), поскольку даже критика переносится подчиненными нередко легче, чем неотмеченная прилежность и надежность;

- исключать неразборчивые публичные разносы, они значительно действеннее в форме индивидуальной беседы, противоположно поощрению;

- моральные и материальные поощрения, аттестацию и продвижения по службе ставить в зависимость от объективных показателей работы, не отдаваясь личным симпатиям или антипатиям;

- создавать условия для личного роста мастерства и квалификации сотрудника;

- помнить, что коллектив желает видеть своего руководителя авторитетным, квалифицированным, принципиальным и справедливым.

Однако стиль руководства определяется не только индивидуально-психологическими различиями руководителя, но и требованиями ситуации: особенностями решаемой коллективом задачи, общими социальнопсихологическими требованиями, которые предъявляются к любому руководителю его подчиненными. Так, ключевым моментом для успешности деятельности руководителя считается соотношение между такими параметрами, как тип решаемой подразделением задачи, структура должностных полномочий и отношения в системе руководитель-подчиненный.

Выбор оптимального стиля руководства определяется характером задачи, стоящей перед коллективом. Так, в случае работы в экстремальной ситуации, когда нет времени на доскональное обсуждение проблемы, более того, когда промедление в принятии решения может привести к людским и материальным потерям, уместно будет проявить черты авторитарного, или директивного, стиля руководства. Исследователи отмечают, что в экстремальных ситуациях, например, такие черты авторитарного стиля руководства, как жесткая критика или жесткий командный тон, воспринимаются подчиненными как адекватные сложившейся ситуации и не вызывают раздражения, обид, напротив, служат индикатором эффективности управления и компетентности руководителя. И напротив, если перед коллективом поставлена творческая задача при отсутствии четких критериев оценки результатов ее решения, то руководитель должен практиковать коллегиальный стиль. В противном случае ему не удастся создать творческую атмосферу, а сам он рискует оказаться отвергнутым коллективом.

Необходимо также учитывать, что в экстремальной ситуации руководитель склонен не выбирать осознанно меры воздействия на коллектив, соответствующие тому или иному стилю, а действовать стереотипно, демонстрируя ведущий для него тип управленческой ориентации. Более того, экстремальная ситуация усугубляет негативные стороны каждого стиля руководства [24;25;26].

\section{Результаты}

Так, для руководителей, ориентированных на решение задачи, может сформироваться установка «выполнить любой ценой, не считаясь с затратами/потерями», для контактоориентированных руководителей ведущим мотивом в принятии решений может стать установка «максимально сберечь людей, физически и психически, даже ценой невыполнения задачи», самоориентированный руководитель сориентируется исключительно на свое индивидуальное мнение по поводу возможных путей решения задачи, не прислушиваясь к разумному мнению членов коллектива, а официально ориентированный руководитель продемонстрирует тактику «ухода» и «сохранения лица», сняв с себя ответственность.

Для эффективного руководства также является первостепенно важной связь между стилем руководства и относительной зрелостью исполнителей, будь то группа или конкретный работник. При этом само понятие зрелости рассматривается не как постоянная характеристика субъекта деятельности, а как достаточно динамичное образование, зависящее от ситуации, в которой разворачивается деятельность.

\section{ОбсужАение}

Необходимо отметить, что ни один из указанных стилей руководства в отрыве от конкретной ситуации не является оптимальным. Опытный руководитель использует элементы тех стилей, необходимость которых диктуется объективными законами развития коллективов и спецификой решаемых задач, в особенности задач, решаемых в условиях дефицита времени, неполной информации или других экстремальных условиях деятельности. Но оптимальный стиль всегда предполагает наличие у руководителя необходимой чувствительности к ситуации, психологической проницательности и внимательности к людям, гибкости мышления.

Проблема социально-психологической компетентности руководителя сопряжена также с достаточно известным понятием коммуникативной компетентности, специальные исследования которой отчетливо обозначились в 60-х годах. Широко известны в этой области труды А.А. Бодалева, Н.В. Кузьминой, Ю.Л. Ханина и др. В 
80-90 гг. вышли в свет работы: А.Л. Журавлева, С.Л. Братченко, Захарова Т.В., Басалаева Н.В., Казакова Т.В., Игнатьева Н.К., Киргизова Е.В., Бахор Т.А. и др [3-8].

В рамках исследований компетентного общения, выработан ряд терминов, которые подводят к понятию социально-психологической компетентности. Среди них можно назвать: «компетентность в общении», «межличностная компетентность», «коммуникабельность», «коммуникативные умения» и др.

\section{Зак^ючение}

Обобщая, можно сказать, что наилучший стиль управления характеризуется следующими показателями:

1. минимизация воздействия;

2. комплексность воздействия;

3. системность воздействия;

4. внутренняя непротиворечивость воздействия.

Очевидно, что при любом стиле, например, считающемся достаточно эффективном демократическом стиле руководства не всегда в полной мере реализуются перечисленные принципы, а, следовательно, этот стиль управления будет не всегда успешен. Что же означают данные характеристики стиля руководства?

Минимизация воздействия в управлении реализуется через использование собственных закономерностей регулируемой системы таким образом, чтобы при небольших и своевременных вмешательствах сила естественных организационных и групповых процессов усиливала воздействие, а не подавляла. Это невозможно без учета закономерности системы, в отношении кото- рой реализуется управление, а это предполагает известную гибкость стратегий поведения, их динамичность, в целом активную позицию руководителя.

Системность воздействия предполагает, что максимальный эффект может быть достигнут только в том случае, когда оно ориентировано на комплекс организационных процессов в целом. Она реализуется через ориентацию на все группы факторов, актуальных для соответствующего уровня компетенции руководителя, то есть можно говорить о широкой ориентации целей руководителя.

Комплексность предполагает, что эффективность воздействия будет тем большей, чем полнее оно ориентировано на весь комплекс мотивов, побуждающих и регулирующих деятельность сотрудников. Комплексность обеспечивается ориентацией на широкий спектр средств и методов воздействия, характерных как для институциональных, так и для в неформальной и неформальной подсистем, и навыками их использования.

Непротиворечивость воздействия обеспечивается тем, что комплексно используемые стимулы не вызывают взаимоисключающих эффектов. Непротиворечивость может иметь место только при сформированных прогностических навыках, особенно касающихся социальных, социально-психологических и психологических последствий принимаемых решений.

В любом случае оценку стиля руководства следует производить с учетом параметров его активности, гибкости и динамичности [9-23].

\section{ЛИТЕРАТУРА}

1. Роберт Блейк и Джейн Моутон. Университет штата Огайо, Мичиганского университета, (B1aке, R., Mouton, I., 1978).

2. Михненко П.А. Теория менеджмента: учебник. 2-е изд., перераб. и доп. М.: Московский финансово-промышленный университет «Синергия», 2014. http://www.consultant.ru/edu/student/download_books/book/mikhnenko_pa_teorija_menedzhmenta/@ КонсультантПлюс, 1997-2019

3. Бодалѐв А.А. К истории освещения существа процессов социальной перцепции //Психологический институт в современном психологическом пространстве: Международные Челпановские чтения - 2014: Московская научно-практическая конференция к 100-летию Торжественного открытия Психологического Института им. Л.Г. Щукиной (1914-2014). Альманах Научного архива Психологического института. Выпуск 7 юбилейный. - М., 2014. С. $475-477$.

4. Кузьмина Н.В. Методы исследования педагогической деятельности.-Л.: Изд-во Ленингр. ун-та, 1970.

5. Ханин Ю.Л. Стресс и тревога в спорте: Международный сб. С 84 научных статей./Сост. Ханин Ю.Л. — М.: Физкультура и спорт, 1983- 288 с.

6. Журавлева А.Л., Фетискин Н.П., Козлов В.В., Мануйлов Г.М. Социально-психологическая диагностика развития личности и малых групп. М. Изд-во Института Психотерапии. 2002.

7. Братченко С.Л. «Диагностика личностно-развивающего потенциала» (Псков, 1997).

8. Захарова Т.В., Басалаева Н.В., Казакова Т.В., Игнатьева Н.К., Киргизова Е.В., Бахор Т.А. Коммуникативная Компетентность: понятие, характеристики // Современные проблемы науки и образования. - 2015. - № 4.; URL: http://science-education.ru/ru/article/view?id=20413 (дата 0бращения: 19.03.2019).

9. Марьин М.И., Иванихина И.В., Ловчан С.И. и др. Оценка управленческой компетентности руководящих кадров ГПС / Методическое пособие. - М.: ВНИИПО, 1998. -117 C.

10. Борисова Е.А. Управление персоналом для современных руководителей // Планирование. Подбор кадров. Оценка деятельности. - СПб.: Питер, 2003 - 445 с.

11. Кабаченко Т.С. Психологические аспекты подбора и расстановки руководителей // Психология работы с персоналом в трудах отечественных специалистов. - СПб.: Питер, 2001. 
12. Кудряшова Л.Д. Каким быть руководителю: психология управленческой деятельности. - Л.: Лениздат, 1986.

13. Васильев Ю.В. Педагогическое управление в школе. - М.: Педагогика, 1990.

14. Коротков Э.М. Качество образования: формирование, факторы и оценка, управление / Гуу. - М., 2002. - 84 с.

15. Зеленская Н.В. Педагогическая концепция управления качеством подготовки офицерских кадров//Автореферат диссертации на соискание ученой степени доктора педагогических наук (13.00.08 - теория и методика профессионального образования). - Санкт-Петербург, УГПС МЧС России, 2008.

16. Козбаченко В.А. -Журнал № 52011 г. «Высшее образование сегодня» Рецензируемое издание ВАК России в области психологии, педагогики и социологии, Постановление совета учебно-методического объединения по образованию в области менеджмента «0б итогах работы Учебно-методического объединения по образованию в области менеджмента в 2010 году и задачах высших учебных заведений по переходу на уровневую систему управленческих кадров» г. Московский 19.04.2011 года. Стр. 33-36.

17. Федоров И.Б Журнал № 52011 г. «Высшее образование сегодня» Московский государственный технический университет им. Н.Э. Баумана «0сновные преимущества получения магистерского образования. Инженер - профессия будущего» стр. 24 - 25.

18. Заболотский В.С. Журнал № 52011 г. «Высшее образование сегодня» Рецензируемое издание ВАК России в области психологии, педагогики и социологии, Дальневосточный государственный технический университет «Наращивание кадрового потенциала высшей школы на основе формирования исследовательской компетентности студентов» стр.50-52.

19. Баскин Ю.Г. Технологический подход к обучению как средство формирования профессиональной компетентности будущих специалистов МЧС России // Вестник Санкт-Петербургского института Государственной противопожарной службы МЧС России, 2006.

20. Дергач А.А. Психологические проблемы профессиональной деятельности кадров государственной службы. Психолого-акмеологические чтения: [Сб. ст.] М.: РАГС, 1998.

21. Дергач А.А., Зазыкин В.Г., Маркова А.К. Психология развития профессионала. - М.: РАГС, 2000.

22. Дергач А.А., Щербина А.В. Эффективность деятельности руководителей в экстремальных ситуациях. - М.: МПАКЦ, 1998.

23. Сайт академика РАО Новикова А.М. Электронная библиотека: полемические статьи// www.anovikov.ru

24. Орлова 0.Н.; Иванихина И.В. Принятие управленческих решений в экстремальных ситуациях (монография). Утверждено Редакционно-издательским советом Академии ГПС МЧС России - М.: Академия ГПС МЧС России, 2015-109 с.

25. Орлова 0.Н. Анализ принятия решений комиссиями по предупреждению и ликвидации по чрезвычайным ситуациям на основе статистических данных и социологических исследованиях (монография). Утверждено Редакционно-издательским советом Академии ГПС МЧС России.- М.: Академия ГПС мЧС России, 2016. - 167с.

26. Орлова 0.Н. Разработка алгоритма по совершенствованию работы в области управления профессиональным воспитанием личного состава ФПС на основе статистических данных (монография). Утверждено Редакционно-издательским советом Академии ГПС МЧС России.- М.: Академия ГПС МЧС России, 2017. $-128 \mathrm{c}$

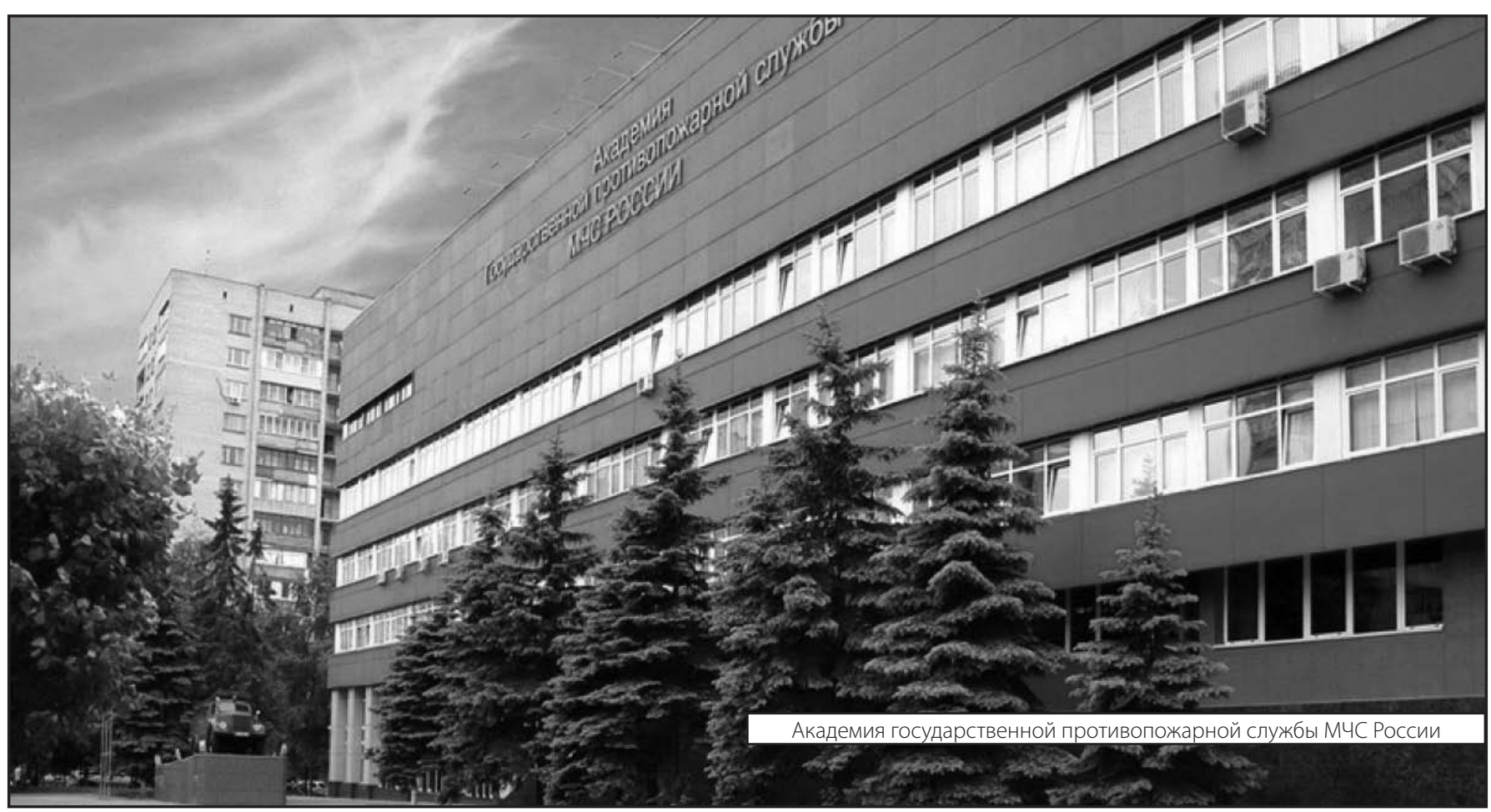

